\title{
Article
}

\section{The Stack Effect on the Thermal-Fluid Behaviour of a Solar Collector}

\author{
Alok Dhaundiyal 1,*(D) and Gedion Habtay Gebremicheal ${ }^{2}$
}

1 Deartment of Energetics, Institute of Process Engineering, Hungarian University of Agriculture and Life Sciences, 2100 Godollo, Pest County, Hungary

2 Doctoral School of Mechanical Engineering, Hungarian University of Agriculture and Life Sciences, 2100 Godollo, Pest County, Hungary; gedion.gebremicheal@phd.uni-mate.hu

* Correspondence: Dhaundiyal.Alok@hotmail.com

check for updates

Citation: Dhaundiyal, A.; Gebremicheal, G.H. The Stack Effect on the Thermal-Fluid Behaviour of a Solar Collector. Energies 2022, 15, 1188. https://doi.org/

$10.3390 /$ en15031188

Academic Editor:

George Kosmadakis

Received: 28 November 2021

Accepted: 3 February 2022

Published: 6 February 2022

Publisher's Note: MDPI stays neutral with regard to jurisdictional claims in published maps and institutional affiliations.

Copyright: (C) 2022 by the authors. Licensee MDPI, Basel, Switzerland. This article is an open access article distributed under the terms and conditions of the Creative Commons Attribution (CC BY) license (https:// creativecommons.org/licenses/by/ $4.0 /)$.

\begin{abstract}
The article investigates the thermal behaviour of a solar collector retrofitted with a natural draught unit. The objective of this work is to draw a comparative line between a system that is equipped with a circular vertical channel and the conventional one. The effectiveness of the solar heating system and how to further improve the prevailing system are examined in this study. The flat plate solar collector was used to assess the dynamics of the system. The Hottel-Whillier-Bliss equation was used to obtain the useful heat gain rate. The instantaneous collector efficiency was reduced by $22.84 \%$. The net heat loss encountered with natural draught was augmented by $10.89 \%$. The net pressure drop along the length of the collector was increased when a solar collector related to the circular chimney. The stagnant temperature of the collector with the natural draught was decreased by $3.20 \%$. The heat loss to the surrounding was computed to be $33.94 \%$ of the net energy received by a solar collector connected with the circular stack. The Fanning friction factor for airflow was reduced in the system equipped with natural draught. The static pressure was marginally dropped at the inlet, whereas it was steeply increased at the outlet of the solar collector. The static pressure would be the same for both systems at collector length $l=0.84 \mathrm{~m}$. The inference can be deducted from the comparative analysis that the air stream flow behind the collector plate and could provide better prospects for a collector unit equipped with natural draught at the exhaust end of the solar dryer.
\end{abstract}

Keywords: heat analysis; pressure-drop; solar collector; performance curves; temperature distribution

\section{Introduction}

The scarcity of conventional resources and the inadequacy of available thermal units are some of the factors which encourage researchers to focus on the application of solar energy in thermal systems. One such system is the drying of perishable food items. This would be traditionally done on open ground. But slowness and the infestation of products with dust and insects demand alternative measures. A cabinet-type dryer (direct gain) was later introduced to carry out the drying process in a fast and controlled manner at a small scale. With time, the mode of heating was bit revolutionised, and the natural circulation of air used to be incited by a blower (forced circulation). The problem with this system was that the temperature of the product was not controlled, and therefore it was replaced by an indirect type of active device. The classification of dryers can also be conducted according to the product that is to be preserved. For example, cabinet-type dryers are mainly used for drying timber, whereas indirect dryers are used for food grains, tea, spices etc. Another aspect of drying system is the solar collector that provides the conditioned air to the drying chamber.

In a recent study, some modifications have been done to enhance the heating characteristic of a drying unit by modifying the solar collector design. Dutta et al. (2021) used a corrugated aluminium alloy plate for an energy analysis of the mixed-mode system. The effect of the mass flow rate on the temperature distribution of the collector plate was 
studied. They noticed that an increase in mass flow rate by $33 \%$ could increase the thermal efficiency of the system by $27 \%$. However, the temperature of the air at the outlet was significantly reduced. The analysis was merely based on a quantitative approach to examine the solar air heater without incorporating the simultaneous effect of pressure and temperature across the parallel plate, despite using a mixed-mode system [1]. Another work involved the thermodynamic study of textile-based solar air collectors (TB-SAC), and it was seen that the exergy of the system was increased by $32 \%$ as compared to the flat plate solar air collector. However, the pressure drop was immensely increased, but the underlying reason for pressure drop across the passage was only sporadically discussed throughout the paper [2]. It was noticed that TB-SAC had the highest efficiency of $62 \%$ at a mass flow rate of $0.62 \mathrm{~kg} \cdot \mathrm{s}^{-1}$, but whether it was affected by the intrinsic factors of the TB-SAC system or not was not discussed [2]. Ammar et al. (2020) discussed solar collector efficiency based on the numerical analysis of a collector using rectangular fins. It was noticed that the relative height of the fin and the pitch of the fin influenced power consumption and the solar collector's efficiency [3]. A selective absorber and a definite number of fins were proposed, but the rationale was missing. The increase in energy consumption of power is not merely based on fin geometry, it also relies inherently on the intensive properties of any thermodynamic system, and this discussion was excluded from their study. Das et al. (2021) compared sand-filled sand coated (SFSC) polycarbonate sheet with an aluminium absorber plate. It was noticed that sand coating on the sheet enhanced the rate of heat transfer due to the redistribution of airflow. It was reported that the impingement of sand on polycarbonate sheets acted as a thermal heat storage medium. An $87 \%$ increase in the mass flow rate of the air reduced thermal energy storage by $10-24 \%$. The work did not include the effects of pressure and temperature on the heat transfer across the proposed design [4]. Similarly, a V-type groove absorber plate was used to enhance the convective heat transfer of the collector by increasing the surface area of the heat transfer as well as the thermal efficiency of the system [5,6]. This type of plate was also reported in previous research [7-10]. Some other innovative designs were also proposed to improve the thermal performance of air-based collectors [11-13]. In some cases, selective coating of absorber plate was also performed to increase the thermal performance of the solar air heaters [14], by using porous/nonporous beds to enhance thermal storage [15,16], or by introducing V-ribs or thin ribs $[17,18]$. Some researchers used different numbers of pass (single or double) air heaters to influence the thermal performance of a solar collector. Nowzari et al. (2014) carried out experiments on both types of passes. Two different perforate covers were incorporated, and it was noticed that the plate having the shorter the distance between holes $(3 \mathrm{~cm})$ had higher efficiency $(46.30 \%)$ than the one having a longer centre-to-centre distance $(6 \mathrm{~cm})$ between the holes, whereas, with the normal glazing, the average efficiency of the collector was $49.98 \%$ at the same mass flow rate $\left(0.032 \mathrm{~kg} \cdot \mathrm{s}^{-1}\right)$ [19]. Mohammadi and Sabzpooshani [20] examined the effects of fins and baffles on the performance of single-pass solar air heaters. It was reported that the involvement of fins and baffles increased the outlet temperature of the air, and thus the collector efficiency was improved. However, increasing the number of fins and baffles might lead to the reverse effect on the overall efficiency of the unit as they increased the power consumption of the pump [20]. Koca et al. (2008) reported that the application of the phase change material $\mathrm{CaCl}_{2} \cdot 6 \mathrm{H}_{2} \mathrm{O}$ in the thermal storage system increased the second and first law efficiencies of the solar collector [21]. Goerng et al. (1997) critically examined a solar collector using the Navier-Strokes momentum and energy equations. It was reported that the Dean number (De) and buoyance were the main factors that indirectly influenced the heat transfer across the fluid boundary. Once the Grashof number (Gr) becomes elevated, the material design has the least relative impact on the performance of the solar collector system [22]. The characteristic of heat transfer across the passage counts not only on the velocity profile but also temperature field.

It was noticed that most of the research works focus on material design and shapes. An alternative effective methodology would be to improve the heat transferring ability of the material. In other words, the properties of fluids have potential that has been overlooked in 
the research. This work is an endeavour to examine those areas which are still unexamined. Dhaundiyal and Atsu (2020) attempted to cover a small section in a similar study where they discussed the interaction of air with the glazing cover and the absorber plate [23]. Likewise, in another study, the exergy of the components and the properties of moist air were comprehensively studied to determine the behaviour of a flat solar collector [24].

Moreover, it was noticed that most of the quantitative analysis was either based on the utilisation of the auxiliary power or in relation to the absorber plate. It was also clear that the increase in mass flow rate influenced the thermal efficiency of the system, but none of the considered approaches was cost-effective, nor was much attention paid to improving the drying unit of the solar-air heating system. The effect of pressure and temperature distribution across the passage was almost absent and the inferences focussed largely on the involvement of material science rather than discussing the rheology of the medium used for drying purposes. In this work, our attention is focused on a flat plate collector that is attached to a drying chamber. The effect on the performance of a solar collector due to the natural draught was examined based on the state properties of a system. This work has also laid emphasises on pressure and temperature distribution across a solar collector.

\section{Materials and Methods}

\subsection{Experimental Set-Up}

The experiments were conducted at the Solar laboratory of the Hungarian University of Agriculture and Life Sciences, Godollo, Hungary. The latitude and the longitude of the site are $47^{\circ} 35^{\prime} 24^{\prime \prime} \mathrm{N}$ and $19^{\circ} 21^{\prime} 36^{\prime \prime} \mathrm{E}$, respectively. The drying unit was coupled to a flat plate collector via a circular duct. The air passage was provided between the absorber plate and the plexiglass cover. The surface of the absorber plate was selectively painted with black enamel paint. A technical drawing of the drying chamber (AutoCAD 2019, Autodesk, Mill Valley, CA, USA) is provided in Figure 1. The flat-plate collector attached to the solar dryer is shown in Figure 2. The thermal and optical properties of the materials used are provided in Table 1. The geometrical dimensions of the materials used for the construction of the solar collector are provided in Table 2. The experiment was performed from 25 September 2019, to 30 September 2019. The thermocouple " $t$ " type was considered for experimental purposes. The data filtering was performed through the Savitzsky-Golay method (MATLAB R2015b, MathWorks, Portola Valley, MA, USA). The scheduled time of data collection was between 10:00 to 15:00 h. The measured solar radiation (Global) was obtained using a pyranometer (Kipp and Zonnen CM11, Delft, the Netherlands) with an accuracy of $\pm 0.1 \mathrm{~W} \cdot \mathrm{m}^{-2}$. The data acquisition was performed through the ADAMS4018(Advantech, Taipei, Taiwan) interface. The air velocity at the inlet of the collector was measured by a digital anemometer (Eurochron EC-MR, Neue Str, Seebach, Germany) with an accuracy of $\pm 0.3 \%$. The heat analysis of the solar collector was performed for each case (1) without natural draught, and (2) with natural draught. The collector mounted on a tilted rack was facing true south (Figure 2). A schematic diagram of the solar drying unit is shown in Figure 3. The energy distribution for the given system was illustrated using the Sankey diagram (IFU, iPoint-systems, Hamburg, Germany).

Table 1. Properties of materials used for construction of the solar drying unit.

\begin{tabular}{|c|c|c|c|c|c|c|c|c|c|}
\hline Components & $\begin{array}{c}k \\
\left(\mathrm{~W} \cdot \mathrm{m}^{-1} \cdot \mathrm{K}^{-1}\right)\end{array}$ & $\begin{array}{c}C \\
\left(\mathrm{~kJ} \cdot \mathrm{kg}^{-1} \cdot \mathrm{K}^{-1}\right)\end{array}$ & $\alpha_{b}$ & $\alpha_{\mathrm{d}}$ & $\tau_{\mathrm{b}}$ & $\tau_{d}$ & $\rho_{\mathrm{b}}$ & $\rho_{\mathrm{d}}$ & $\varepsilon$ \\
\hline Plexiglass cover & $0.190[25]$ & - & 0.080 & 0.079 & 0.887 & 0.940 & 0.050 & 0.052 & $0.78[26]$ \\
\hline Copper plate & 385 [27] & 387 [28] & \multicolumn{2}{|c|}{0.65 [27] } & - & - & - & - & 0.95 \\
\hline Polystyrene & 0.130 [29] & - & - & - & - & - & - & - & - \\
\hline Plywood & $0.038[30]$ & - & - & - & - & - & - & - & - \\
\hline
\end{tabular}


Table 2. Geometrical details of material used for construction of solar collector.

\begin{tabular}{ccc}
\hline Material & Dimensions & Thickness \\
\hline Glass cover & $1160 \times 460 \mathrm{~mm}^{2}$ & $4 \mathrm{~mm}$ \\
\hline Plywood box & $1200 \times 500 \times 150 \mathrm{~mm}^{3}$ & $\begin{array}{c}20 \mathrm{~mm} \text { (side), } 2 \mathrm{~mm} \text { (bottom), } \\
2 \mathrm{~mm} \text { (reveals approx.) }\end{array}$ \\
\hline Copper plate & $1160 \times 460 \mathrm{~mm}^{2}$ & $1.2 \mathrm{~mm}$ \\
\hline Polystyrene & $1160 \times 460 \mathrm{~mm}^{2}$ & $80 \mathrm{~mm}$ \\
\hline Air space & $1160 \times 460 \mathrm{~mm}^{2}$ & $60 \mathrm{~mm}$ \\
\hline PVC duct & $200 \times 45 \mathrm{~mm}^{2}$ & $3.17 \mathrm{~mm}$ \\
\hline
\end{tabular}

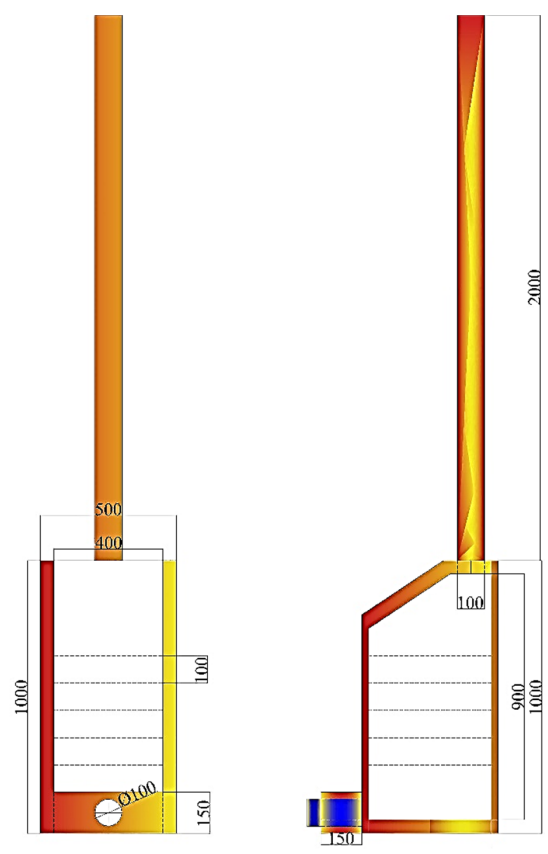

Figure 1. Technical drawing of a solar dryer with circular chimney.

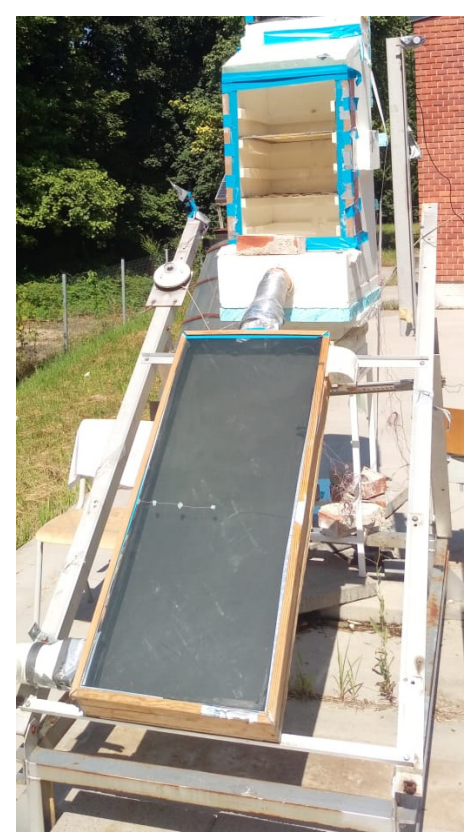

Figure 2. A flat plate collector assembled with a solar dryer. 


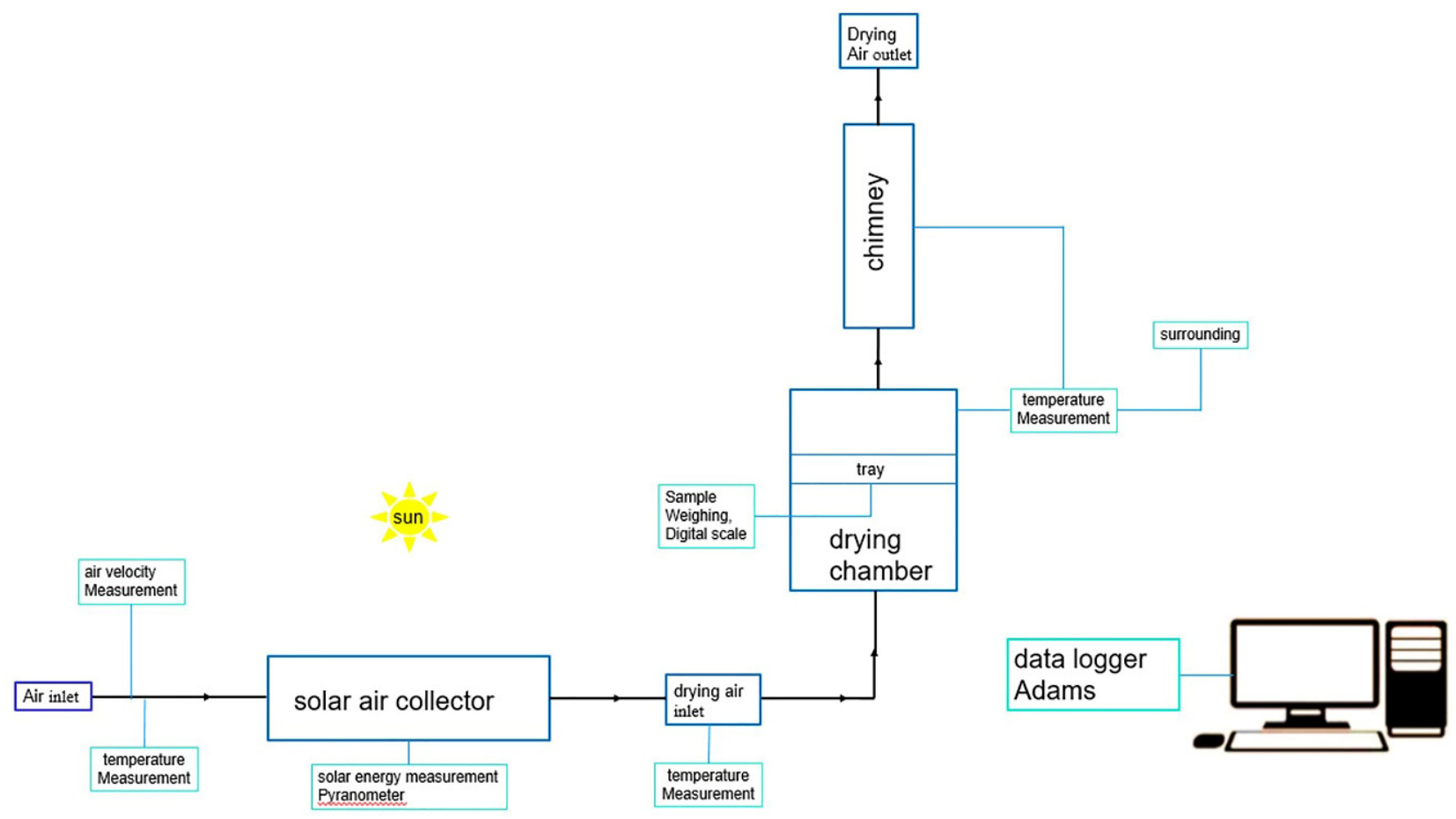

Figure 3. Schematic diagram of the solar drying unit Dhaundiyal et al., 2021 [31].

\subsection{Performance Analysis of the Collector}

The analysis of the solar collector is based on a quasi-steady static state situation. Some assumptions related to the measurement of the equivalent heat transfer coefficient and temperature distribution were taken to solve the energy equation for the absorber plate, airstream and glazing cover. The insolation for both systems was considered the same for comparative evaluation. The heat transfer coefficient of the plate with the air stream was assumed to be the same as that the air stream has with the cover plate. As the temperature difference between $\left(T_{\mathrm{pm}}-T_{\mathrm{bm}}\right)$ was relatively small (nearly of the order of $10 \mathrm{~K}$ ), it was replaced by the product of $\left(T_{\mathrm{pm}}-T_{\mathrm{bm}}\right)\left\{\frac{\left(T_{\mathrm{pm}}+T_{\mathrm{bm}}\right)}{2}\right\}^{3}$.

The equivalent radiative heat transfer coefficient $h_{\mathrm{r}}$ can be defined by Equation (1) [32]

$$
h_{\mathrm{r}}=\frac{\left[4 \sigma\left\{\frac{\left(T_{\mathrm{pm}}+T_{\mathrm{bm}}\right)}{2}\right\}^{3}\right]}{\left(\frac{1}{\varepsilon_{\mathrm{p}}}+\frac{1}{\varepsilon_{\mathrm{c}}}-1\right)}
$$

Similarly, the effective heat transfer coefficient between airstream and absorber plate was given by Equation (2) [32]

$$
h_{\mathrm{e}}=\left[h_{\mathrm{fp}}+\frac{h_{\mathrm{r}} h_{\mathrm{fc}}}{h_{\mathrm{r}}+h_{\mathrm{fc}}}\right]
$$

The convective heat transfer coefficient to the heated air was determined by the correlation suggested by Kays [33] for smooth surfaces (Equation (3))

$$
\frac{h_{f p} \cdot L_{e}}{k}=0.0158 R e^{0.8}(\text { Valid for } 2300<R e)
$$


For laminar flow, Equation (4) can be used [33]

$\frac{h_{f p} \cdot L_{e}}{k}=0.53 \times(G r \sin \beta \cdot P r)^{\frac{1}{4}}\left(\right.$ Valid for $\left.10^{4}<G r \cdot \operatorname{Pr}<10^{9}\right)($ For inclined plate $)$

The Blasius equation was used for determining the pressure drop across the parallel plate duct (smooth surfaces) (Equation (3))

$$
f=0.079 \times R e^{-0.25}
$$

The useful heat gain rate by airstream was calculated through the Hottel-Whillier-Bliss equation (Equation (5)) [32]

$$
q_{\mathrm{u}}=F_{\mathrm{R}} A_{\mathrm{p}}\left[S-U_{\mathrm{l}}\left(T_{\mathrm{fi}}-T_{\mathrm{a}}\right)\right]
$$

The calculation of the instantaneous diffuse radiation was based on the relation given by De Jong.

The instantaneous extra-terrestrial solar radiation was computed by Equation (6) [28]

$$
I_{\mathrm{O}}=S_{\mathrm{cs}}\left[1+0.033 \cos \left(\frac{360 n}{365}\right)\right] \cos \theta
$$

The following relations (Equations (7) and (8)) between daily diffuse radiation and the daily global radiation are valid for $0.35 \leq \frac{I_{\mathrm{g}_{\mathrm{di}}}}{I_{\mathrm{o}_{\mathrm{di}}}}<0.75$ and $0.07 \leq \frac{I_{\mathrm{g}_{\mathrm{di}}}}{I_{\mathrm{odi}_{\mathrm{di}}}}<0.35$, respectively.

$$
\begin{gathered}
\frac{I_{\mathrm{d}_{\mathrm{di}}}}{I_{\mathrm{gdi}}}=1.33-\frac{1.46 I_{\mathrm{g}_{\mathrm{di}}}}{I_{\mathrm{O}_{\mathrm{di}}}} \\
\frac{I_{\mathrm{d}_{\mathrm{di}}}}{I_{\mathrm{gdi}}}=1-2.3\left(\frac{I_{\mathrm{g}_{\mathrm{di}}}}{I_{\mathrm{O}_{\mathrm{di}}}}-0.07\right)^{2}
\end{gathered}
$$

The instantaneous diffuse radiation was estimated by Equation (9) [34]

$$
I_{\mathrm{d}}=\frac{I_{\mathrm{o}} \times I_{\mathrm{d}_{\mathrm{di}}}}{I_{\mathrm{O}_{\mathrm{di}}}}
$$

Note: The supplementary information is provided in Appendix A.

\section{Results and Discussion}

The comparative assessment of the natural draught system with the conventional type of dryer was based on heat analysis and temperature and pressure distribution along the length of the collector. The deviation of the radiation fluxes with time is illustrated in Figure 4. It was noticed that the diffuse flux varied constantly with time. A small increase in the diffuse radiation $\left(I_{\mathrm{d}}\right)$ was seen at noon, whereas it was reduced at 15:00 $(18,000 \mathrm{~s})$. Similarly, the beam radiation $\left(I_{\mathrm{b}}\right)$ was relatively lower than diffuse radiation from 10 a.m. $(0 \mathrm{~s})$ to $11 \mathrm{a} . \mathrm{m}$. (3600 s). The diffuse radiation had its peak at noon (7200 s). A drastic decrease in beam radiation was observed at a time interval of 12,780-16,380 s (13:33 to 14:25). The maximum value of beam radiation was noticed at 12:32 (9120 s). In the same way, the maximum global radiation was recorded at 12:31 (9060 s). The reduction in global radiation was noticed to begin at 13:00 $(10,800)$. From 13:51 to 14:38, a marginal increase in global radiation was observed. The flux received by the absorber plate was relatively higher than the beam and diffuse radiation except from 13:49 to 13:55. No deviation between the flux absorbed by the absorber and diffuse radiation was recorded at 13:37, 13:49, 13:55, 14.02 and 14:11. The effect of the tilt and shape factors could be seen in the magnitude of the flux incident on the top cover plate (plexiglass). The trend of deviation was similar to global radiation, but a steep fluctuation was noticed. The reason for the rapid undulation was the simultaneous change in the solar angles with the magnitude of global radiation, 
whereas the diffuse radiation was mainly based on deviation in the altitude angle with time.

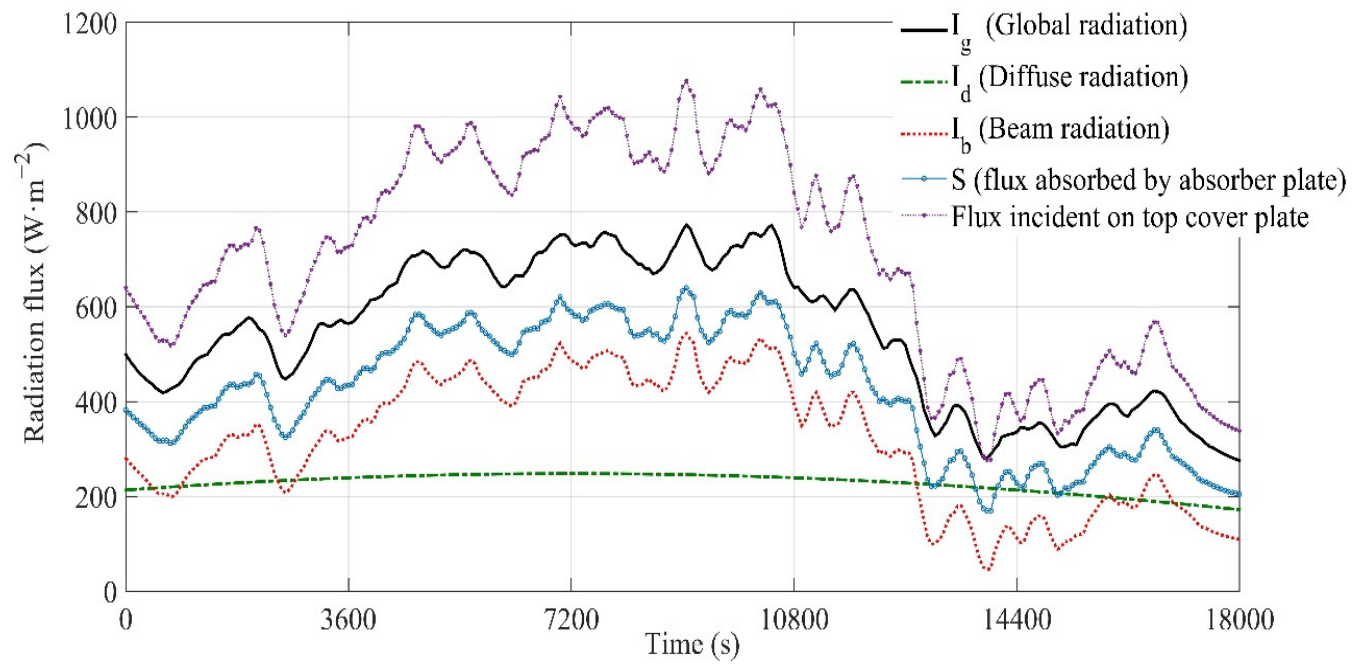

Figure 4. Record of radiation flux measured on a clear day.

The changes in the equivalent radiative (a) and effective heat transfer coefficients are illustrated in Figure 5. The change in radiative heat transfer coefficient for both the systems was at maximum from 10:00 (0 s) to 10:50 (3000 s), whereas it was at its minimum at 13:20 $(12,000 \mathrm{~s})$. The peak value of $h_{\mathrm{r}}$ for the solar collector equipped with the natural draught was seen at 11:30 (5400 s). On the other hand, the peak value of $h_{\mathrm{r}}$ was attained at 12:50 (10,200 s) for the conventional model. A delay of $4320 \mathrm{~s}$ to reach maximum values was observed in the conventional model. The maximum value of $h_{\mathrm{r}}$ for the natural draught-equipped unit was estimated to be approximate twice the $h_{\mathrm{r}}$ of the conventional model. A sudden reduction in $h_{\mathrm{r}}$ in the natural draught unit began at 13:20. The lowest possible value of $h_{\mathrm{r}}$ derived for the natural draught unit was 5.46\% lower than for the conventional model. The major decrease in the conventional model was noticed to be $22 \%$ higher than that obtained by the natural draught model. It can be deduced from the $h_{\mathrm{r}}$ values that the radiative heat gain would be relatively high before noon for a unit equipped with natural draught, whereas it would be larger in the conventional unit from 12:40 to 13:30 (9600-12,600 s). The net average value of $h_{\mathrm{r}}$ for the conventional model was $0.90 \%$ higher than the value of $h_{\mathrm{r}}$ for the natural draught system. However, the effective heat transfer coefficient $\left(h_{\mathrm{e}}\right)$ between the absorber plate and the airstream was appreciably higher than the unit with the natural draught system. The net average value of $h_{\mathrm{e}}$ was reduced by $68.31 \%$ in the unit without natural draught. The maximum $h_{\mathrm{e}}$ for the natural draught system was attained at 13:20 $(12,000 \mathrm{~s})$, while it was achieved by the conventional model at noon (7200).

The maximum value of $h_{\mathrm{e}}$ for a conventional system was estimated to be $68.42 \%$ lower than the value obtained for a unit with the natural draught system. It can be concluded that a system equipped with natural draught could significantly enhance the effective heat transfer between air and absorber plate for the constant temperature difference between the air stream and absorber plate. The reason for a significant increase in $h_{\mathrm{e}}$ is the drastic increase in the Reynolds number $(R e)$. It was found that the airflow was transient when the solar collector was attached with a dryer equipped with a circular chimney, whereas it was laminar for a dryer without it. On the other hand, radiative heat transfer predominately relies on temperature distribution, along with the bulk flow of the air stream. The involvement of convective heat transfer $\left(h_{\mathrm{fp}}\right)$ (flow driven) would have priority over temperature-driven radiative heat flow. 
(a)

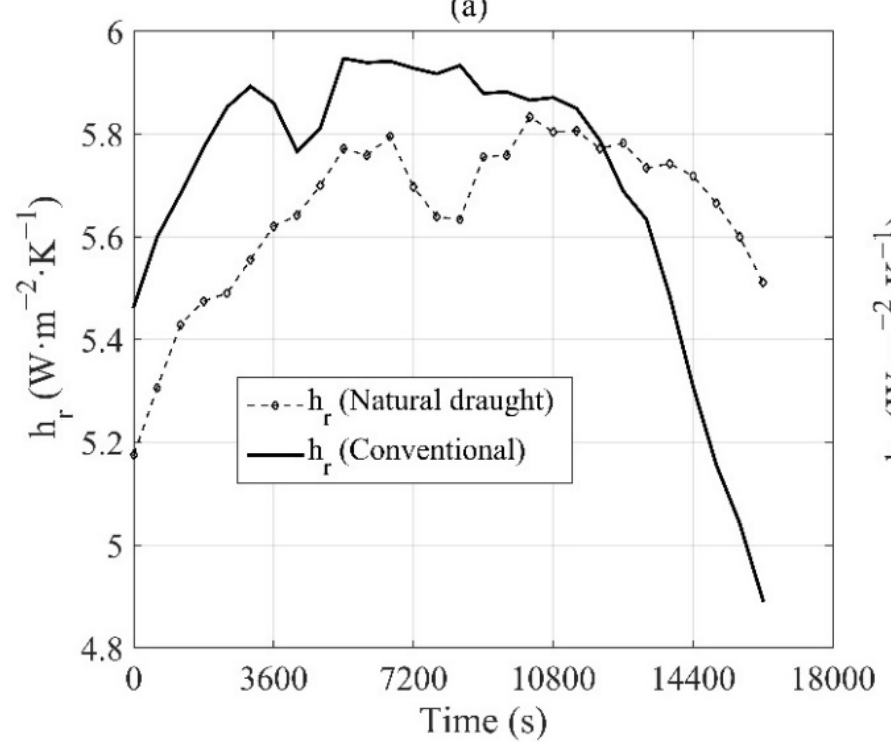

(b)

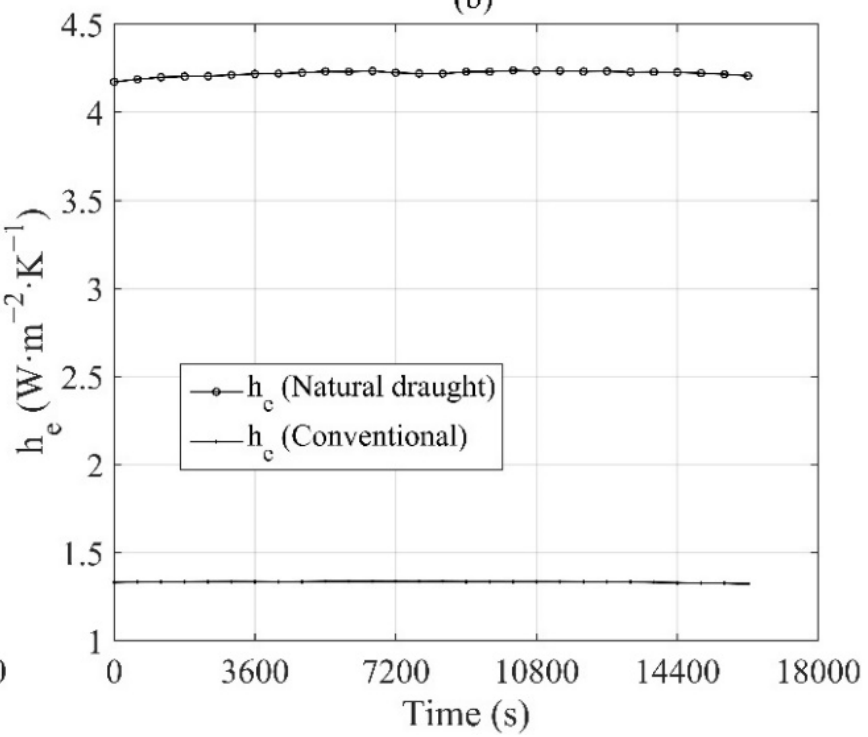

Figure 5. Radiative and effective heat transfer coefficient between the absorber and air stream: (a) radiative heat transfer coefficient $\left(h_{\mathrm{r}}\right),(\mathbf{b})$ effective heat transfer coefficient $\left.\left(h_{\mathrm{e}}\right)\right)$.

Some other important parameters, namely the collector efficiency $\left(F^{\prime}\right)$ and heat removal $\left(F_{R}\right)$ factors for both systems are shown in Figure 6a-d. The distribution pattern of the collector efficiency factor $F^{\prime}$ is essentially the same for both systems ( $a$-Natural draught; $b$ Conventional). However, the sudden increase in the ratio of the actual useful heat gains to the gain which would have happened if the absorber plate were at the local air temperature occurred at 12:20 (8400 s) for the natural draught system, while it was around 11:10 (4200 s) for the conventional unit. The maximum possible value of $F^{\prime}$ fell before noon (10:00 to 11:50) for a unit equipped with the natural draught. On the other hand, it saw an exponential increase from 13:00-14:30 (1,0800-16,200 s) for the conventional unit. The peak value of $F^{\prime}$ of the unit with natural draught was 17\% higher than that obtained with the conventional unit. Similarly, the standard deviation in $F^{\prime}$ for natural draught and conventional types were 0.001091 and 0.0006 , respectively. These data clearly show the collector efficiency factor $F^{\prime}$ would be largely the same throughout the heating process for both the systems and only the quantitative effect would be seen after incorporating the circular chimney at the exhaust end of the solar drying unit. Since the construction is the same for both systems, the flow-driven $h_{\mathrm{fp}}$ significantly influenced the actual useful heat gain rate. On the contrary, the undulation in the heat removal factor was noticed to be perceivable in the case of the drying unit attached to a circular chimney (Figure $6 \mathrm{c}, \mathrm{d}$ ). The pattern of variation in the heat removal factor $\left(F_{\mathrm{R}}\right)$ was similar to the collector efficiency factor, $F^{\prime}$. The average value of the heat removal factor for the conventional unit was increased by $16.93 \%$ when it was compared with the unit attached with a circular chimney. The standard deviation in heat removal factors, $F_{\mathrm{R}}$ for the natural draught and conventional units were 0.00021 and 0.000209 , respectively. It could be seen that the overall change in heat removal factor within the given period was negligibly low. The maximum estimated value of $F_{\mathrm{R}}$ for a natural draught system was 0.407 , whereas it was 0.475 for the conventional system. It was noticed that $F_{\mathrm{R}}$ dropped to the same degree as $F^{\prime}$ increased for the unit equipped with natural draught. The main reason was that the equivalent overall loss coefficient $\left(U_{1}\right)$ was exceptionally increased for the given flow arrangement. The value of $U_{1}$ was estimated to be decreased by $89.61 \%$ for a solar collector without natural draught (conventional). 
(a) Nautral Draught

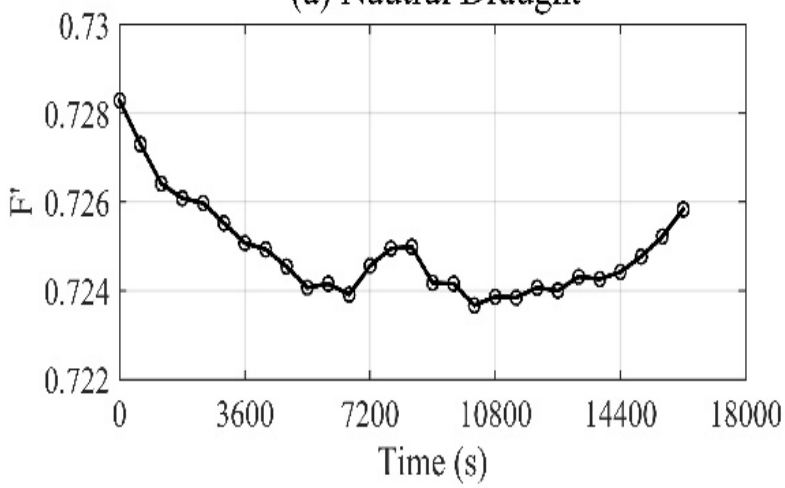

(c) Nautral Draught

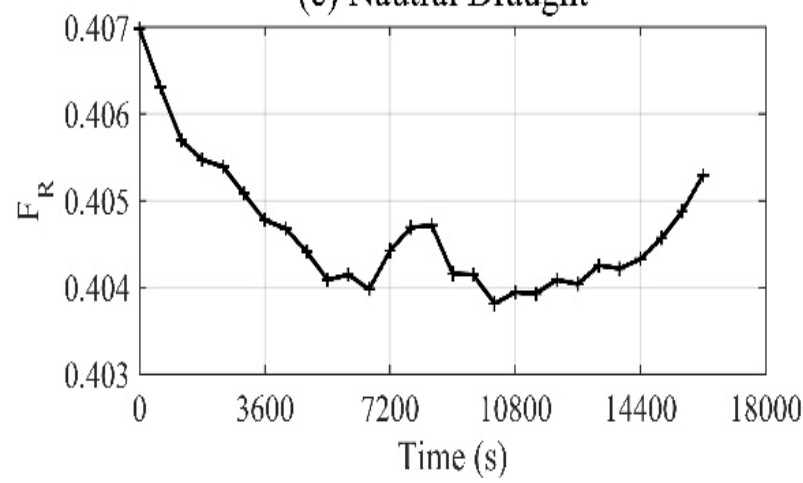

(b) Conventional

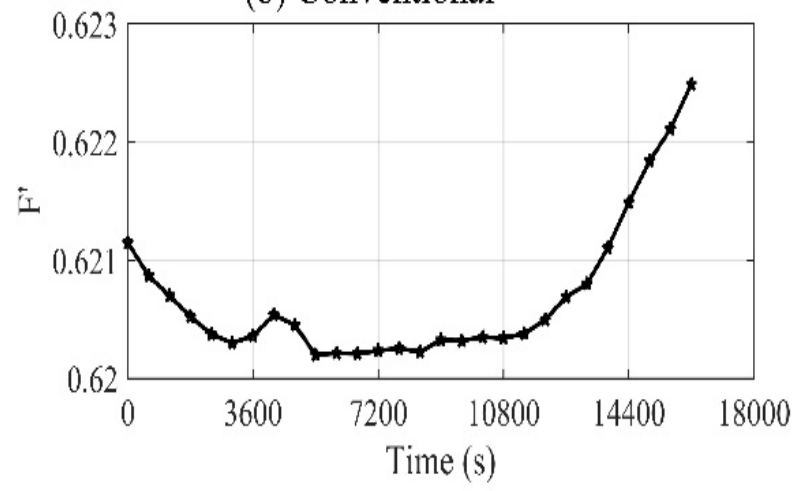

(d) Conventional

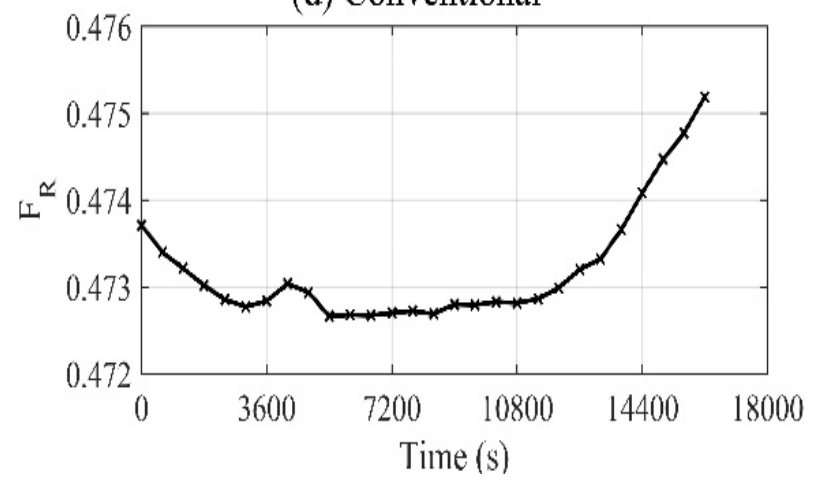

Figure 6. Variations in the collector efficiency $\left(F^{\prime}\right)$ and heat removal $\left(F_{\mathrm{R}}\right)$ factors with time: $(\mathbf{a}, \mathbf{c})$ : dryer with natural draught; $(\mathbf{b}, \mathbf{d})$ : dryer without draught (conventional)).

The derived values of $\eta_{1}$ were plotted against the ratio of different measured inlet air and ambient temperatures to the total incident radiation on the cover plate in Figure 7. The intercept on the $Y$-axis would give $\left(0.889 \times F_{\mathrm{R}} \times(\tau \alpha)\right.$ average $)$, whereas the slope of the line would provide $\left(0.889 \times F_{\mathrm{R}} \times U_{1}\right)$. The scatter of the data was noticed to be uniformly distributed for the system with natural draught, whereas it was closely clustered as $\left(T_{f i}-T_{a}\right)$ increased for the conventional system attached to the solar collector. These results imply that the increase in the temperature of the air at the inlet of the solar collector would insignificantly impact the collector efficiency. However, this was not the case while examining the performance of collectors equipped with natural draught. It is also clear from a plot that the overall effective heat loss coefficient would make the instantaneous collector efficiency $\left(\eta_{1}\right)$ decrease rapidly, for a constant heat removal rate. To make the solar collector work efficiently, the temperature difference must be kept as low as possible to counter the heat across the cover plate.

With the help of the least square method, the following equations were obtained for the system operating with a circular chimney (Equation (10)) and without it (Equation (11)):

$$
\begin{aligned}
& \eta_{1}=-86 \times \frac{\left(T_{f i}-T_{a}\right)}{I_{T}}+22 \\
& \eta_{\mathrm{I}}=-13 \times \frac{\left(T_{f i}-T_{a}\right)}{I_{T}}+25
\end{aligned}
$$




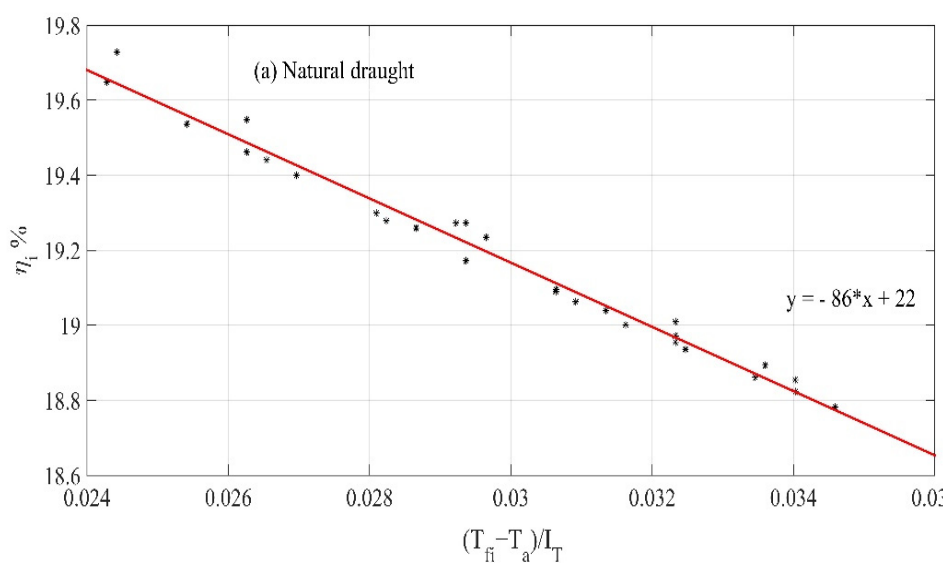

(a)

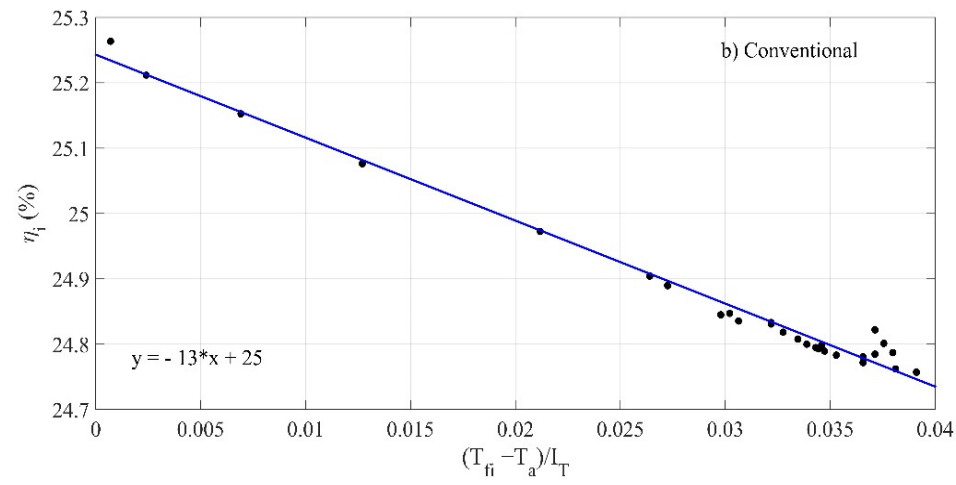

(b)

Figure 7. Efficiency curve for solar collectors: (a) natural draught; (b) conventional.

The changes in temperature and pressure for both systems is illustrated in Figure 8a-d. The air temperature (Figure 8a) for the solar collector running under the natural draught system had a margin drop from 12:10 to 12:30 (7800-9000 s), whereas this drop took place between 11:00 and 11:20 (3600-4800 s) for the unit equipped with the conventional dryer (without a chimney). A significant drop in temperature was seen from 16: 00 to 17:00 for the solar collector attached to the conventional dryer. The lowest air temperature determined for the unit with a natural draught system was found to be $4.04 \%$ higher than that derived for the solar collector with the conventional system. However, the maximum air temperature was lower, by $0.27 \%$, as compared to the corresponding value for the conventional system. The air temperature was found to be constant for the conventional unit, while it was relatively erratic for the solar collector equipped with the natural draught unit. The temperature difference absorber plate and the airstream temperatures were significantly lower than those obtained for the conventional system. The temperature difference $\left(T_{p}-T_{f}\right)$ was estimated to drop by $72.86 \%$ at the inlet of a solar collector equipped with natural draught when it was compared with the corresponding value for a unit attached with the conventional system. In the context of a solar collector with a conventional dryer, the temperature difference between the absorber plate and the backplate was increased by $1.01 \%$ for a solar collector unit with natural draught. The heat transfer through conduction was marginally dropped across the copper plate by adding a circular chimney with the dryer. The temperature deviation between the stagnant temperature $\left(T_{\mathrm{s}}\right)$ and the absorber plate temperature was decreased by $80 \%$ for the conventional unit as compared to the corresponding value for the natural draught unit. The reason for the remarkable variation between these two types of solar dryers was the flow behaviour of the air stream, which is transient for a system operating with a circular chimney. Consequently, it would assist the convective heat transfer between airstream and absorber plate and enable 
the dissipation of heat through the glass cover. The stagnant temperature is the maximum possible temperature a solar collector can have if the actual heat gain becomes minimised with time. The steady temperature distribution was achieved for a solar collector operating under a natural draught unit. The net total pressure distribution for both systems can be seen in Figure $8 \mathrm{c}, \mathrm{d}$. The total energy line (TEL) at the outlet had attained its maximum value at 12:50 (10,200 s), which is relatively $4 \%$ higher than the corresponding value estimated with a solar dryer without the circular chimney. However, the net total pressure before noon for the solar collector equipped with natural draught available was $0.89 \%$ lower than the corresponding value computed for the solar collector operated with the conventional dryer. The average net pressure at the outlet of the solar collector (or inlet of the dryer) was marginally increased by $1.43 \%$ when the dryer was equipped with a circular chimney. Seeing the pressure distribution patterns for both systems, it could be concluded that the pressure would be steadier during the daytime without a natural draught unit, while it would be the opposite if equipped with a circular chimney.

The energy diagrams for a solar collector connected to a natural draught and a collector with a conventional dryer are shown in Figure 9a,b. The solar energy absorbed by the copper plate was estimated to be $53.15 \%$ of the total energy incident on the glass cover. The input for both systems was kept constant and the effect of the circular chimney on the output of the solar collector was determined. The actual useful heat energy received by air was $36 \%$ of the total energy absorbed by the copper plate, whereas it was augmented by $30 \%$ while using the same solar collector without a chimney. The overall losses (convective, conduction and radiative) were evaluated for both cases, and it was found to be $63.86 \%$ for natural draught, which is approximately $11 \%$ higher than that obtained for the conventional solar collector. Although the heat transfer coefficient was significantly improved for the system with natural draught, it also increased the convective losses to ambient through the airstream.

The variations in the static pressure along the air passage to vertical height are shown in Figure 10. The effect of natural draught at the inlet and outlet of the solar collector can be seen through the relative change in the magnitude of pressure force along with the absorber plate. The effect of density variation to mean fluid temperature was also incorporated. It was noticed that the static pressure force at the inlet would marginally decrease for the solar collector equipped with the natural draught, whereas a drastic increase in the static pressure force was seen at a constant datum level. The static pressure force would be the same at $0.31 \mathrm{~m}$ from the outlet of the collector for both systems. The maximum static pressure force for a conventional unit would be applied at $0.64 \mathrm{~m}$ and $0.34 \mathrm{~m}$ from the outlet of the collector for the conventional and natural draught units, respectively. The static pressure force derived for the natural draught unit was found to be increased by $0.0079 \%$ at the outlet of the collector when it was compared with the conventional unit.

The average values of the performance parameters for both systems are tabulated in Table 3. The equivalent overall loss coefficient for the conventional system was found to be $89.61 \%$ lower than that obtained for the natural draught unit. On the other hand, the actual useful heat gain rate for a conventional system was $29.67 \%$ higher than the heat gain rate derived for a natural draught unit. The pressure drop was convincingly decreased by $93.10 \%$ when the solar collector was operated without a natural draught unit. The average estimated temperature of the absorber plate $\left(T_{\mathrm{pm}}\right)$ was increased $28.42 \%$ as compared to the $T_{\text {pm }}$ derived from a solar collector running with natural draught. Similarly, the backplate temperature was also increased by $31.14 \%$ for the solar collector operated with a conventional dryer. However, the mean fluid temperature $\left(T_{\mathrm{fm}}\right)$ was marginally increased by $0.29 \%$. Likewise, the stagnation temperature $\left(T_{\mathrm{s}}\right)$, another important factor for designing an efficient solar collector, was also impacted. An increase of $3.31 \%$ was seen in $T_{\mathrm{s}}$ with the solar collector running without a natural draught unit. The average terrestrial solar radiation was found to be $809.570 \mathrm{~W} \cdot \mathrm{m}^{-2}$. The average collector efficiency $\left(\eta_{1}\right)$ was decreased by $22.84 \%$ for the solar collector with a circular chimney. The average static pressure force $\left(F_{\text {static }}\right)$ would be the same in both cases. The heat transfer coefficient 
for the front side $\left(U_{t}\right)$ was reduced by $67.84 \%$ when a solar collector was operated with natural draught. Similarly, the heat transfer coefficient $\left(U_{\mathrm{b}}\right)$ for the backside of a solar collector without natural draught was also reduced by $24.52 \%$. It was noticed that the Prandtl number $(P r)$ was slightly increased for the solar collector equipped with the natural draught. It had eventually allowed the dominance of momentum diffusivity over the thermal field. Therefore, the convective losses would be sufficiently high for a solar collector operating with the natural draught unit. The results were compared with a similar type of solar collector operated under forced and free convection, and they were in good agreement with experimentally derived values of the performance parameters $[35,36]$.
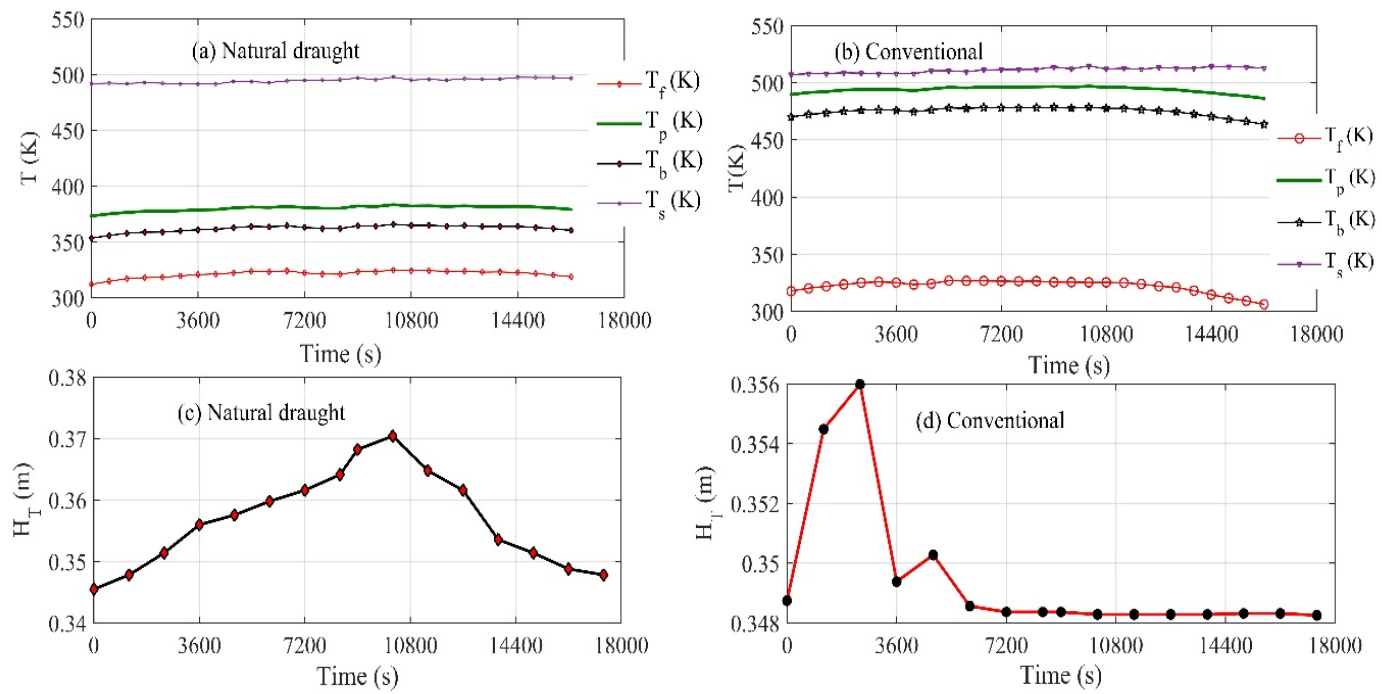

Figure 8. Temperature distribution and total pressure head at the outlet ((a) temperature distribution for a unit equipped with natural draught system, (b) temperature distribution for the conventional unit, (c) total pressure head for a unit equipped with natural draught system, (d) total pressure head for a unit equipped with the conventional unit).

Energy Diagram

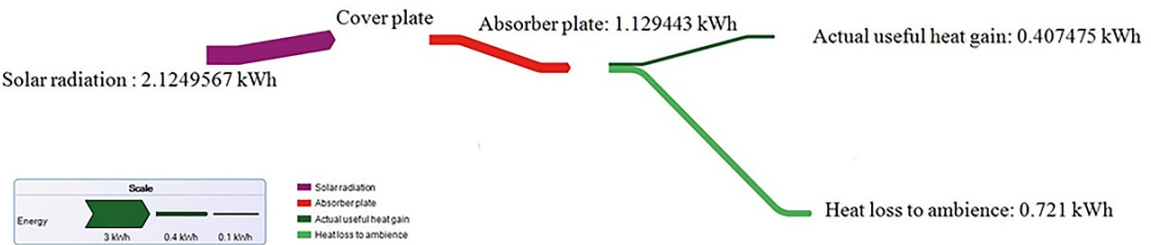

(a)

Energy Diagram

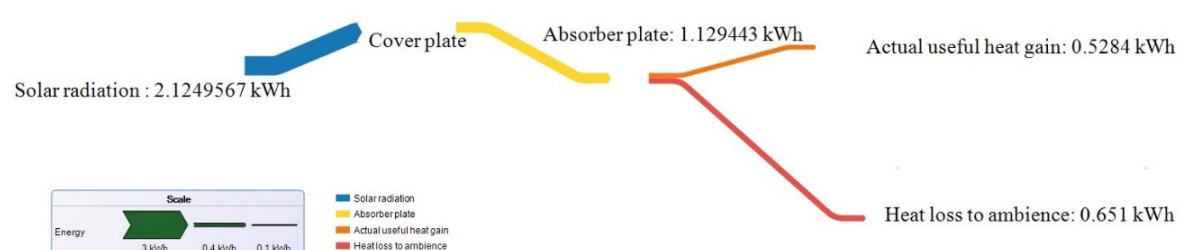

(b)

Figure 9. Energy diagrams for two different systems ((a): a system with natural draught; (b): a system with a conventional dryer). 


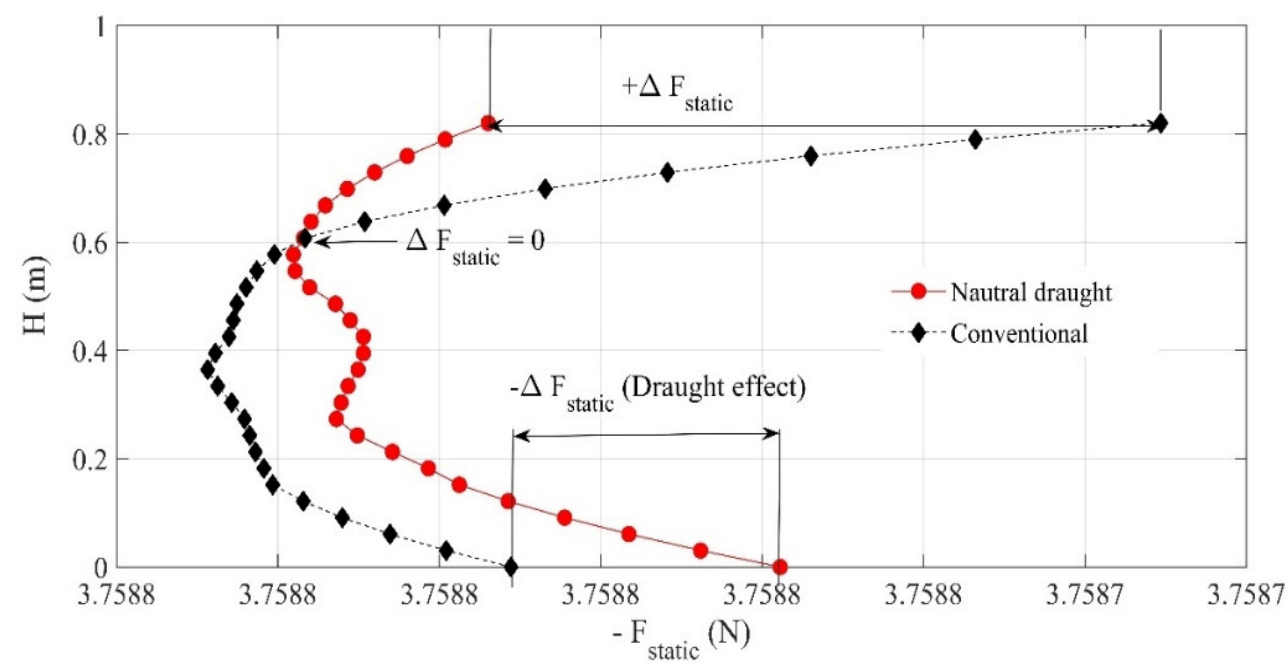

Figure 10. The variation of the static pressure force $\left(F_{\text {static }}\right)(\mathrm{N})$ along the airstream passage.

Table 3. Parametric information related to the performance of a solar collector, based on average values.

\begin{tabular}{|c|c|c|}
\hline Parameters & Natural Draught & Conventional \\
\hline$h_{\mathrm{fp}}\left(\mathrm{W} \cdot \mathrm{m}^{-2} \cdot \mathrm{K}^{-1}\right)$ & 2.491 & 0.706 \\
\hline$R e$ & 2961.614 & 610.934 \\
\hline$G r$ & $1.67 \times 10^{8}$ & $7.37 \times 10^{8}$ \\
\hline $\operatorname{Pr}$ & 0.77 & 0.78 \\
\hline$h_{\mathrm{r}}\left(\mathrm{W} \cdot \mathrm{m}^{-2} \cdot \mathrm{K}^{-1}\right)$ & 5.574 & 5.625 \\
\hline$h_{\mathrm{e}}\left(\mathrm{W} \cdot \mathrm{m}^{-2} \cdot \mathrm{K}^{-1}\right)$ & 4.210 & 1.334 \\
\hline$F_{\mathrm{R}}$ & 0.405 & 0.473 \\
\hline$F^{\prime}$ & 0.724 & 0.621 \\
\hline$F_{\text {static }}(\mathrm{N})$ & 3.758 & 3.758 \\
\hline$U_{1}\left(\mathrm{~W} \cdot \mathrm{m}^{-2} \cdot \mathrm{K}^{-1}\right)$ & 2.128 & 0.221 \\
\hline$q_{\mathrm{u}}(\mathrm{W})$ & 81.495 & 105.680 \\
\hline$h_{\mathrm{L}}(\mathrm{Pa})$ & 0.058 & 0.004 \\
\hline$U_{\mathrm{t}}\left(\mathrm{W} \cdot \mathrm{m}^{-2} \cdot \mathrm{K}^{-1}\right)$ & 2.0805 & 0.669 \\
\hline$U_{\mathrm{b}}\left(\mathrm{W} \cdot \mathrm{m}^{-2} \cdot \mathrm{K}^{-1}\right)$ & 0.318 & 0.240 \\
\hline$q_{1}(\mathrm{~W})$ & 144.393 & 130.208 \\
\hline$\overline{\eta_{i}} \%$ & $19.180 \%$ & $24.860 \%$ \\
\hline$T_{\mathrm{pm}}(\mathrm{K})$ & 380.130 & 488.182 \\
\hline$T_{\mathrm{bm}}(\mathrm{K})$ & 362.118 & 474.788 \\
\hline$T_{\mathrm{fm}}(\mathrm{K})$ & 321.310 & 322.25 \\
\hline$T_{\mathrm{S}}(\mathrm{K})$ & 494.648 & 511.036 \\
\hline$H_{\mathrm{T}}(\mathrm{m})$ & 0.355 & 0.350 \\
\hline$S_{0}\left(\mathrm{~W} \cdot \mathrm{m}^{-2}\right)$ & \multicolumn{2}{|c|}{809.570} \\
\hline$A M$ & \multicolumn{2}{|c|}{1.703} \\
\hline$\frac{L}{L_{\mathrm{e}}}$ & \multicolumn{2}{|c|}{11} \\
\hline$f$ & 0.0107 & 0.016 \\
\hline
\end{tabular}




\section{Conclusions}

The change in the thermal and fluid-dynamic behaviour of the solar collector was examined when it was connected with a conventional dryer and the dryer with a circular stack. The effect on its performance with a circular chimney was evaluated with the common assumption that the system would be quasi-steady static. The salient findings obtained after analysing the performance of the same unit under different situations are summarised below:

1. Natural draught would influence the momentum diffusivity of the airstream, which consequently impacts the heat removal factor.

2. The transient flow of the airstream would bring less steadiness in the total energy line and the solar dryer would have peak pressure during noontime, whereas it would happen early in the day for the conventional dryer (without any auxiliary unit). Moreover, it pushed the system to the forced convection regime.

3. The stagnant temperature of a solar collector with natural draught was reduced by $3.2 \%$ and the deviation between $T_{\mathrm{s}}$ and $T_{\mathrm{pm}}$ was relatively increased. Conversely, the deviation between $T_{\mathrm{fm}}$ and $T_{\mathrm{pm}}$ was reduced by $64.55 \%$.

4. The static pressure negligibly increased while running the solar collector with the natural draught unit.

5. The collector efficiency was reduced by $22.84 \%$ using the circular chimney.

6. The overall losses were increased by $11 \%$ for the solar collector attached to the dryer operated with a chimney.

7. The hydrostatic boundary layer would be impacted if the solar collector operated with a circular chimney.

8. The collector efficiency factor $F^{\prime}$ increased by $16.58 \%$, whereas the collector heat removal factor $F_{\mathrm{R}}$ decreased by $14.37 \%$ for the same collector running with natural draught.

9. The equivalent loss coefficient $U_{1}$ was reduced by $89.61 \%$ without natural draught.

10. The pressure drop was drastically increased while operating the solar collector with natural draught.

Natural draught enhanced the convective heat transfer, but at the same time, the losses were also simultaneously increased. To improve the given system, it could be beneficial if the airstream were allowed to flow between insulated polystyrene and the absorber plate. On the other hand, the velocity of the air stream must not have been high enough for the flat plate solar collector, or else the addition of the circular stack would have had the opposite effect on the performance of the solar thermal system.

Author Contributions: Conceptualization, A.D. and A.D.; methodology, A.D.; software, A.D.; validation, A.D.; formal analysis, A.D.; investigation, A.D.; resources, A.D.; data curation, G.H.G.; software, G.H.G.; writing — original draft preparation, A.D.; writing—review and editing, A.D.; visualization, A.D.; All authors have read and agreed to the published version of the manuscript.

Funding: This research received no external funding.

Institutional Review Board Statement: Not applicable.

Informed Consent Statement: Not applicable.

Data Availability Statement: Not applicable.

Conflicts of Interest: The authors declare no conflict of interest. 


\begin{tabular}{|c|c|c|}
\hline \multicolumn{3}{|c|}{ Abbreviations } \\
\hline Symbol & Description & Unit \\
\hline$\theta$ & Zenith angle & $\circ$ \\
\hline$\delta$ & Declination angle & $\circ$ \\
\hline$\phi$ & Latitude & $\circ$ \\
\hline$\beta$ & Angle of tilt & $\circ$ \\
\hline$\omega$ & Hour angle & $\circ$ \\
\hline$r_{\mathrm{b}}$ & The tilt factor for beam radiation & - \\
\hline$r_{\mathrm{d}}$ & The tilt factor for diffuse radiation & - \\
\hline$r_{\mathrm{r}}$ & The tilt factor for reflected radiation & - \\
\hline$I_{\mathrm{b}}$ & Hourly beam radiation & $W \cdot m^{-2}$ \\
\hline$I_{\mathrm{g}}$ & Hourly global radiation & $\mathrm{W} \cdot \mathrm{m}^{-2}$ \\
\hline$I_{\mathrm{d}}$ & Hourly diffuse radiation & $\mathrm{W} \cdot \mathrm{m}^{-2}$ \\
\hline$S$ & The flux absorbed in the absorber plate & $\mathrm{W} \cdot \mathrm{m}^{-2}$ \\
\hline$I_{0}$ & Extra-terrestrial radiation & $\mathrm{W} \cdot \mathrm{m}^{-2}$ \\
\hline$S_{\mathrm{CS}}$ & Solar constant & $W \cdot m^{-2}$ \\
\hline$\rho_{\mathrm{g}}$ & Ground reflectivity & - \\
\hline$\eta_{\mathrm{i}}$ & The instantaneous collection efficiency & - \\
\hline$\theta_{2}$ & Angle of refraction & $\circ$ \\
\hline K & The extinction coefficient & $m^{-1}$ \\
\hline$\tau$ & Transmissivity of the cover plate & - \\
\hline$\tau_{\mathrm{r}}$ & Transmissivity based on reflection and refraction & - \\
\hline$\tau_{\mathrm{a}}$ & Transmissivity is derived by considering only absorption & - \\
\hline$\varepsilon$ & Emissivity & - \\
\hline$p, c$ & Subscript for plate and glazing cover & - \\
\hline$\sigma$ & Stefan-Boltzmann constant & $\mathrm{W} \cdot \mathrm{m}^{-2} \cdot \mathrm{K}^{-4}$ \\
\hline$q_{\mathrm{u}}$ & Useful heat gain & $\mathrm{W}$ \\
\hline$q_{1}$ & $\begin{array}{l}\text { The rate at which heat is lost by convection and } \\
\text { re-radiation from the top, and by conduction }\end{array}$ & \\
\hline & and convection from the bottom and sides. & W \\
\hline$A_{\mathrm{c}}$ & The collector gross area & $\mathrm{m}^{2}$ \\
\hline$\delta_{\mathrm{c}}$ & The thickness of the cover plate & $\mathrm{m}$ \\
\hline$h$ & Subscript for horizontal surface & - \\
\hline$F_{\mathrm{R}}$ & Heat removal factor & - \\
\hline$F^{\prime}$ & Collector efficiency factor & - \\
\hline$A_{\mathrm{p}}$ & Absorber plate area & $\mathrm{m}^{2}$ \\
\hline$U_{1}$ & The equivalent overall loss coefficient & $\mathrm{W} \cdot \mathrm{m}^{-2} \cdot \mathrm{K}^{-1}$ \\
\hline$h_{\mathrm{fp}}$ & Heat transfer coefficient between air and plate & $\mathrm{W} \cdot \mathrm{m}^{-2} \cdot \mathrm{K}^{-1}$ \\
\hline$h_{\mathrm{r}}$ & Equivalent radiative heat transfer coefficient & $\mathrm{W} \cdot \mathrm{m}^{-2} \cdot \mathrm{K}^{-1}$ \\
\hline$h_{\mathrm{e}}$ & $\begin{array}{l}\text { The effective heat transfer coefficient between } \\
\text { the absorber plate and airstream }\end{array}$ & $\mathrm{W} \cdot \mathrm{m}^{-2} \cdot \mathrm{K}^{-1}$ \\
\hline$T_{\mathrm{fi}}$ & The inlet temperature of the air & $\mathrm{K}$ \\
\hline$T_{\mathrm{a}}$ & The temperature of the surrounding air & $\mathrm{K}$ \\
\hline$T_{\mathrm{pm}}$ & The average temperature of the absorber plate & K \\
\hline$T_{\mathrm{bm}}$ & The average temperature of the backplate & K \\
\hline$T_{\mathrm{fm}}$ & The mean temperature of the air stream & K \\
\hline$T_{\mathrm{s}}$ & The stagnation temperature of the absorber plate & K \\
\hline$h_{\mathrm{L}}$ & Pressure-drop in the duct & $\mathrm{Pa}$ \\
\hline$A M$ & Air Mass & - \\
\hline$N u$ & Nusselt number & - \\
\hline $\operatorname{Re}$ & Reynolds number & - \\
\hline Le & Equivalent diameter & $\mathrm{m}$ \\
\hline$H_{\mathrm{T}}$ & Total pressure head at the outlet of the solar collector & $\mathrm{m}$ \\
\hline
\end{tabular}




\section{Appendix A}

The zenith angle $(\theta)$ relationship with declination, latitude, tilt angle and hour angle for horizontal $(h)$ and vertical planes is defined by Equations (A1) and (A2), respectively.

$$
\begin{gathered}
\cos \theta=\sin \delta \sin (\phi-\beta)+\cos \delta \cos \omega \cos (\phi-\beta) \\
\cos \theta_{\mathrm{h}}=\sin \delta \sin \phi+\cos \delta \cos \omega \cos \phi
\end{gathered}
$$

The tilt factors $(r)$ for beam $\left(r_{\mathrm{b}}\right)$, diffuse $\left(r_{\mathrm{d}}\right)$ and reflected $\left(r_{\mathrm{r}}\right)$ radiations are estimated by the following Equations (A3)-(A5), respectively. It is to be noted here that $\frac{(1+\cos \beta)}{2}$ and $\frac{(1-\cos \beta)}{2}$ are the radiation shape factors with respect to a tilted surface and the surrounding ground, respectively. Moreover, the ground reflectivity is assumed to be 0.2 .

$$
\begin{gathered}
r_{\mathrm{b}}=\frac{\cos \theta}{\cos \theta_{\mathrm{h}}} \\
r_{\mathrm{d}}=\frac{(1+\cos \beta)}{2} \\
r_{\mathrm{r}}=\rho_{\mathrm{g}} \frac{(1-\cos \beta)}{2}
\end{gathered}
$$

The net solar radiation received on a titled surface at any instant is computed by Equation (A6).

$$
I_{\mathrm{T}}=I_{\mathrm{b}} r_{\mathrm{b}}+I_{\mathrm{d}} r_{\mathrm{d}}+I_{\mathrm{g}} r_{\mathrm{r}}
$$

The global solar radiation in Equation (A6) can also be determined by Equation (A7)

$$
I_{\mathrm{g}}=I_{\mathrm{b}}+I_{\mathrm{d}}
$$

The flux absorbed in the absorber plate is estimated by Equation (A8)

$$
S=I_{\mathrm{b}} r_{\mathrm{b}}(\tau \alpha)_{\mathrm{b}}+\left(I_{\mathrm{d}} r_{\mathrm{d}}+I_{\mathrm{g}} r_{\mathrm{r}}\right)(\tau \alpha)_{\mathrm{d}}
$$

The transmissivity of the cover plate is obtained by clubbing the reflection-refractionbased transmissivity and the transmissivity based on Absorption

$$
\tau=\tau_{\mathrm{r}} \tau_{a}
$$

Furthermore, the reflection-refraction-based transmissivity $\left(\tau_{\mathrm{r}}\right)$ can be derived by taking the mean of transmissivities of different components of polarised light (Equation (A10))

$$
\tau_{\mathrm{r}}=\left(\frac{\tau_{\mathrm{rI}}+\tau_{\mathrm{r} I I}}{2}\right)
$$

The absorption-based transmissivity $\left(\tau_{\mathrm{a}}\right)$ can be determined by Bouger's law. The relation of $\tau_{\mathrm{a}}$ with the extinction coefficient, angle of refraction and the thickness of glazing cover is given by Equation (A11).

$$
\tau_{\mathrm{a}}=e^{-K \delta_{\mathrm{c}} / \cos \theta_{2}}
$$

The ratio of the flux absorbed by the copper plate to the flux incident on the cover plate is represent by the transmissivity-absorptivity product $(\tau \alpha)$. The relation between diffuse reflectivity and $(\tau \alpha)$ is given by Equation (A12)

$$
(\tau \alpha)=\frac{\tau \alpha}{1-(1-\alpha) \rho_{d}}
$$


The flux transfer between the cover and Absorber plate is determined by solving the Energy balance equations for absorber plate (A13), glazing cover (A14) and the air stream (A15).

$$
\begin{aligned}
S= & h_{\mathrm{fp}}\left(T_{\mathrm{pm}}-T_{\mathrm{f}}\right)+h_{\mathrm{r}}\left(T_{\mathrm{pm}}-T_{\mathrm{c}}\right)+U_{\mathrm{b}}\left(T_{\mathrm{pm}}-T_{\mathrm{a}}\right) \\
& h_{\mathrm{r}}\left(T_{\mathrm{pm}}-T_{\mathrm{c}}\right)=U_{\mathrm{t}}\left(T_{\mathrm{c}}-T_{\mathrm{a}}\right)+h_{\mathrm{fc}}\left(T_{\mathrm{c}}-T_{\mathrm{f}}\right) \\
& \frac{\dot{m} C_{\mathrm{p}}}{W} \frac{d T_{f}}{d x}=h_{\mathrm{fp}}\left(T_{\mathrm{pm}}-T_{\mathrm{f}}\right)+h_{\mathrm{fc}}\left(T_{\mathrm{c}}-T_{\mathrm{f}}\right)
\end{aligned}
$$

The equivalent overall loss coefficient and the collector efficiency factor are given by the Equations (A16) and (A17).

$$
\begin{gathered}
U_{1}=\frac{\left(U_{\mathrm{t}}+U_{b}\right)\left(h_{f c} h_{f p}+h_{f c} h_{r}+h_{f p} h_{r}\right)+U_{t} U_{b}\left(h_{f c}+h_{f p}\right)}{h_{f c} h_{r}+h_{f p} U_{t}+h_{f p} h_{r}+h_{f c} h_{f p}} \\
F^{\prime}=\frac{\left(h_{f c} h_{r}+h_{f p} U_{t}+h_{f p} h_{r}+h_{f c} h_{f p}\right)}{\left(U_{t}+h_{r}+h_{f c}\right)\left(U_{b}+h_{r}+h_{f p}\right)-h_{r}^{2}}
\end{gathered}
$$

The relationship between heat removal factor and the collector efficiency factor are given by

$$
F_{R}=\frac{\dot{m} C_{p}}{U_{l} A_{p}}\left[1-\exp \left\{-\frac{F^{\prime} U_{l} A_{p}}{\dot{m} C_{p}}\right\}\right]
$$

The instaneous collector efficiency of the collector can be computed from Equation (A19)

$$
\eta_{i}=\frac{q_{u}}{A_{c} I_{T}}
$$

\section{References}

1. Dutta, P.; Dutta, P.P.; Kalita, P.; Goswami, P.; Choudhury, P.K. Energy analysis of a mixed-mode corrugated aluminium alloy (AlMn1Cu) plate solar air heater. Mater. Today Proc. 2021, 47, 3352-3357. [CrossRef]

2. Ural, T. Experimental performance assessment of a new flat-plate solar air collector having textile fabric as absorber using energy and exergy analyses. Energy 2019, 188, 116116. [CrossRef]

3. Ammar, M.; Mokni, A.; Mhiri, H.; Bournot, P. Numerical analysis of solar air collector provided with rows of rectangular fins. Energy Rep. 2020, 6, 3412-3424. [CrossRef]

4. Das, B.; Mondol, J.D.; Negi, S.; Smyth, M.; Pugsley, A. Experimental performance analysis of a novel sand coated and sand filled polycarbonate sheet based solar air collector. Renew. Energy 2020, 164, 990-1004. [CrossRef]

5. Zulkifle, I.; Alwaeli, A.H.; Ruslan, M.H.; Ibarahim, Z.; Othman, M.Y.H.; Sopian, K. Numerical investigation of V-groove air-collector performance with changing cover in Bangi, Malaysia. Case Stud. Therm. Eng. 2018, 12, 587-599. [CrossRef]

6. Heydari, A.; Mesgarpour, M. Experimental analysis and numerical modeling of solar air heater with helical flow path. Sol. Energy 2018, 162, 278-288. [CrossRef]

7. Naphon, P.; Kornkumjayrit, K. Numerical analysis on the fluid flow and heat transfer in the channel with V-shaped wavy lower plate. Int. Commun. Heat Mass Transf. 2008, 35, 839-843. [CrossRef]

8. Karim, M.; Hawlader, M. Performance investigation of flat plate, v-corrugated and finned air collectors. Energy 2006, 31, 452-470. [CrossRef]

9. Sundén, B.; Sköldheden, T. Heat transfer and pressure drop in a new type of corrugated channels. Int. Commun. Heat Mass Transf. 1985, 12, 559-566. [CrossRef]

10. Hernández, A.L.; Quiñonez, J.E. Analytical models of thermal performance of solar air heaters of double-parallel flow and double-pass counter flow. Renew. Energy 2013, 55, 380-391. [CrossRef]

11. Natarajan, E.; Sathish, R. Role of nanofluids in solar water heater. Int. J. Adv. Manuf. Technol. 2009, 43, 746-757. [CrossRef]

12. Farajzadeh, E.; Movahed, S.; Hosseini, R. Experimental and numerical investigations on the effect of $\mathrm{Al} 2 \mathrm{O} 3 / \mathrm{TiO} 2 \mathrm{H} 2 \mathrm{O}$ nanofluids on thermal efficiency of the flat plate solar collector. Renew. Energy 2017, 118, 122-130. [CrossRef]

13. Winston, R. Principles of solar concentrators of a novel design. Sol. Energy 1974, 16, 89-95. [CrossRef]

14. El-Sebaii, A.; Al-Snani, H. Effect of selective coating on thermal performance of flat plate solar air heaters. Energy 2010, 35, 1820-1828. [CrossRef]

15. Dissa, A.; Ouoba, S.; Bathiebo, D.; Koulidiati, J. A study of a solar air collector with a mixed "porous" and "non-porous" composite absorber. Sol. Energy 2016, 129, 156-174. [CrossRef] 
16. Chaichan, M.T.; Abaas, K.I.; Kazem, H.A. Design and assessment of solar concentrator distillating system using phase change materials (PCM) suitable for desertic weathers. Desalination Water Treat. 2015, 57, 14897-14907. [CrossRef]

17. Hans, V.; Saini, R.; Saini, J. Heat transfer and friction factor correlations for a solar air heater duct roughened artificially with multiple v-ribs. Sol. Energy 2010, 84, 898-911. [CrossRef]

18. Sharma, S.; Kalamkar, V. Experimental and numerical investigation of forced convective heat transfer in solar air heater with thin ribs. Sol. Energy 2017, 147, 277-291. [CrossRef]

19. Nowzari, R.; Aldabbagh, L.; Egelioglu, F. Single and double pass solar air heaters with partially perforated cover and packed mesh. Energy 2014, 73, 694-702. [CrossRef]

20. Mohammadi, K.; Sabzpooshani, M. Comprehensive performance evaluation and parametric studies of single pass solar air heater with fins and baffles attached over the absorber plate. Energy 2013, 57, 741-750. [CrossRef]

21. Koca, A.; Oztop, H.F.; Koyun, T.; Varol, Y. Energy and exergy analysis of a latent heat storage system with phase change material for a solar collector. Renew. Energy 2008, 33, 567-574. [CrossRef]

22. Goering, D.; Humphrey, J.; Greif, R. The dual influence of curvature and buoyancy in fully developed tube flows. Int. J. Heat Mass Transf. 1997, 40, 2187-2199. [CrossRef]

23. Dhaundiyal, A.; Atsu, D. The effect of thermo-fluid properties of air on the solar collector system. Alex. Eng. J. 2021, 61, 2825-2839. [CrossRef]

24. Dhaundiyal, A.; Gebremicheal, G.H. The effect of psychrometry on the performance of a solar collector. Environ. Sci. Pollut. Res. 2021, 29, 13445-13458. [CrossRef]

25. Plastic Properties. Available online: https://www.emcoplastics.com/assets/pdf/plexiglas/Plexiglas $\% 20$ General\%20 Information\%20and\%20Properties.pdf (accessed on 10 November 2021).

26. Zwinkels, J.C.; Davidson, W.F.; Dodd, C.X. Optical properties of UV transmitting acrylics for use in a heavy water Cerenkov detector. Appl. Opt. 1990, 29, 3240-3248. [CrossRef] [PubMed]

27. Carvill, J. Mechanical Engineer's Data Handbook; Elsevier: Oxford, UK, 1993

28. Holman, J.P. Heat Transfer, 9th ed.; McGraw-Hill, Inc.: New York, NY, USA; Boston, MA, USA, 2002.

29. Pelsmakers, S. The Environmental Design Pocketbook; RIBA Publishing: London, UK, 2019. [CrossRef]

30. Billington, M.; Barnshaw, S.; Bright, K.; Crooks, A. The Building Regulations: Explained and Illustrated; John Wiley \& Sons: Hoboken, NJ, USA, 2017.

31. Dhaundiyal, A.; Gebremichael, G.H.; Atsu, D. Comprehensive Analysis of Solar Dryer with a Natural Draught. Energy Sources Part A Recovery Util. Environ. Eff. 2021. [CrossRef]

32. Whillier, A. Performance of black-painted solar air heaters of conventional design. Sol. Energy 1964, 8, 31-37. [CrossRef]

33. Kays, W.M. Convective Heat and Mass Transfer; McGraw-Hill Book Co.: New York, NY, USA, 1967.

34. De Jong, J.B.R.M. Een Karakterisering van de Zonnestraling in Nederland; Doctoraalverslag: Eindhoven, The Netherlands, 1980.

35. Rani, P.; Tripathy, P. Thermal characteristics of a flat plate solar collector: Influence of air mass flow rate and correlation analysis among process parameters. Sol. Energy 2020, 211, 464-477. [CrossRef]

36. Garcia, R.P.; Oliveira, S.D.R.; Scalon, V.L. Thermal efficiency experimental evaluation of solar flat plate collectors when introducing convective barriers. Sol. Energy 2019, 182, 278-285. [CrossRef] 